\title{
A COMUNICAÇÃO COMO PROCESSO DE INTERAÇÃO E DE INTEGRAÇÃ̃O NO SISTEMA FAMILIAR - OS VALORES
}

\author{
Maria Olívia Dias ${ }^{1}$
}

\begin{abstract}
Resumo: O tema que aqui tratamos "Comunicação como processo de interação e de integração no sistema familiar" tem como principal objetivo analisar, por um lado, a comunicação como fator de interação e integração dos membros da família na dinâmica do grupo familiar, e, por outro lado, relevar a importância dos valores familiares como instrumentos de qualidade nas relações internas do sistema. A família está de facto, e pela sua natureza, na base da orientação para formar cidadãos de hoje e de amanhã, por isso é que ela é tão importante. A vida familiar determina a qualidade da vida da sociedade. Quanto mais forte for a família no seu processo de comunicação e interação, melhor proporciona aos seus membros as condições para que cada um, na sua especificidade, cumpra as funções que lhe são próprias, como pai, como mãe e como filho. A comunicação na família permite a aprendizagem de valores e padrões de comportamento que podem ser positivos ou negativos nas relações que mantêm o sistema familiar em equilíbrio/desequilíbrio. Assim, reúnem-se neste documento algumas reflexões sobre a relação família-comunicação; a comunicação no sistema familiar; os desafios que hoje se colocam à família na integração das crianças, e, por fim, a comunicação na família enquanto referência de valores. A família deve revalorizar e consolidar os seus valores, não só para o seu bem, mas também para o bem social. É neste sentido, que se pretende responder a interrogações cada vez mais vulneráveis, tanto na comunicação como nas relações familiares.
\end{abstract}

Palavras-chave: Comunicação, Família, Sistema Familiar, Valores

\section{Title: COMMUNICATION AS A PROCESS OF INTERACTION AND INTEGRATION IN THE FAMILY SYSTEM - VALUES}

Abstract: The theme explored in this article "Communication as a process of interaction and connection in the Family system" has the

\footnotetext{
${ }^{1}$ Prof. Auxiliar do Departamento de Economia, Gestão e Ciências Sociais do Pólo de Viseu da Universidade Católica Portuguesa.E-mail: profaoliviadias@gmail.com
} 
main goal of analysing, in one hand, the communication as a factor of interaction and connection of family members in the family group dynamics, on the other hand, underline the importance of family values as instruments of quality in internal relations in the system. Family is, in fact, by its nature, the guidance basis to create citizens for today and tomorrow, which demonstrates its importance. Family life determines the society quality of life. As stronger the Family is in its communication and connection processes, better conditions are provided to its members, so that each one fulfils, in its specificity, a task as a father, as a mother and as a son. Communication in the Family allows learning about values, behaviour patterns that can sometimes be positive or negative in relations that maintain family system balanced/unbalanced.

Therefore this article gathers some reflections about family communication relation; communication in family system; nowadays challenges to families about children integration and finally family communication as a reference of values.

Family should revalue and consolidate its values, not only for its wellbeing, but also to the social wellbeing. This way, this article wants to answer some vulnerable questions in communication as well as in family relations.

Keywords: Communication, Family, Family System, Values.

\section{INTRODUÇÃO}

$\mathrm{O}$ atual contexto em que vivemos obriga-nos a reflexões profundas e alargadas sobre a especificidade e necessidades dos diferentes tipos de família que as sociedades integram. Ao observarmos esta realidade apercebemo-nos que a sua complexidade salienta a importância cada vez mais sentida por quem estuda a realidade familiar.

Se a evidência no que se refere a um número crescente de diferentes tipos de famílias é incontestável, estas novas formas de estrutura e dinâmica familiar não se despem a nosso ver, da essência que define a família como um grupo social em que os membros estão ligados por um conjunto de laços afetivos, mas também por uma complexidade ampla e cada vez maior de relações interpessoais (Dias, 2000).

Os diferentes tipos de família são entidades dinâmicas, todos eles, com a sua própria identidade, compostas por membros unidos por laços de sanguinidade, afetividade ou interesse e que convivem por um determinado espaço de tempo durante o qual constroem uma história de vida única e irreplicável (Giddens, 2004; Alarcão \& Relvas, 2002; Amaro, 2006, p.71; Dias, 2011, p.143).

A família, como primeiro núcleo de relação do indivíduo, exige compromisso, enquanto um todo, o que obriga cada um dos seus membros a comunicar, ou seja, a estabelecer relações comunicacionais. 
Neste sentido há uma envolvência que passa por treino, aprendizagem, prática e uma série de atitudes que envolvem não só as palavras, o sentido compreensivo e lógico de estrutura, mas também os gestos, toda a linguagem do corpo que cada elemento utiliza nas relações de interação com todo o sistema familiar.

Uma família com poucas ligações entre os seus membros necessita, obviamente, de encontrar os meios adequados à satisfação das suas necessidades e do seu bem-estar integrado. Este desafio, que é sem dúvida muito complexo, só é possível quando através da comunicação existirem entre os seus membros relações interativas que permitam que cada indivíduo, no seu próprio desenvolvimento, se sinta parte integrante do grupo primário que é a família.

A crescente complexidade e os novos problemas não nos permitem, no contexto deste trabalho, na sua dimensão, ensaiar uma explicação completa do fenómeno que envolve o sistema familiar. Contudo, atrevemo-nos a chamar a atenção para quatro pontos centrados nos seguintes aspetos: No primeiro, analisaremos, ainda que sumariamente, os conceitos de família e comunicação dando especial ênfase às relações entre os membros da família; no segundo abordaremos a comunicação no sistema familiar; o terceiro fará referência aos desafios colocados à família na integração das crianças; e, por fim, concluímos com o quarto, e último ponto, a comunicação na família enquanto referência de valores.

Desta forma, pretendemos compreender a importância que a comunicação tem no seio familiar como instrumento de interação por um lado, e de integração por outro. A comunicação, ramo que se ocupa das relações entre as pessoas, é a ideia que nos interessa na análise deste texto e não teorias ligadas à informação que são mais direcionadas para outras áreas.

\section{CONCEITOS ORIENTADORES - FAMÍLIA E COMUNICAÇÃO}

\subsection{Sobre o Conceito de Família}

A conceção da família, e consequentemente, a sua organização e dinâmica, tem sido alvo de transformações, ao longo do tempo, influenciada pelos valores e conhecimentos que caracterizam os diferentes períodos da história.

Embora considerada uma das instituições mais persistentes no tempo, a mudança social reflete-se amplamente na instituição familiar, tendo sido arrastada para novas realidades às quais tem procurado adaptar-se (Saraceno \& Naldini, 2003).

De facto, a velocidade imprimida à mudança depende, de uma forma direta, dos fatores culturais, económicos, sociais, tecnológicos e 
demográficos que contribuíram de forma decisiva para as alterações na estrutura, nas funções e em toda a dinâmica, tanto interna como externamente. Esquematizando temos como resultado a figura I:

FIGURA I

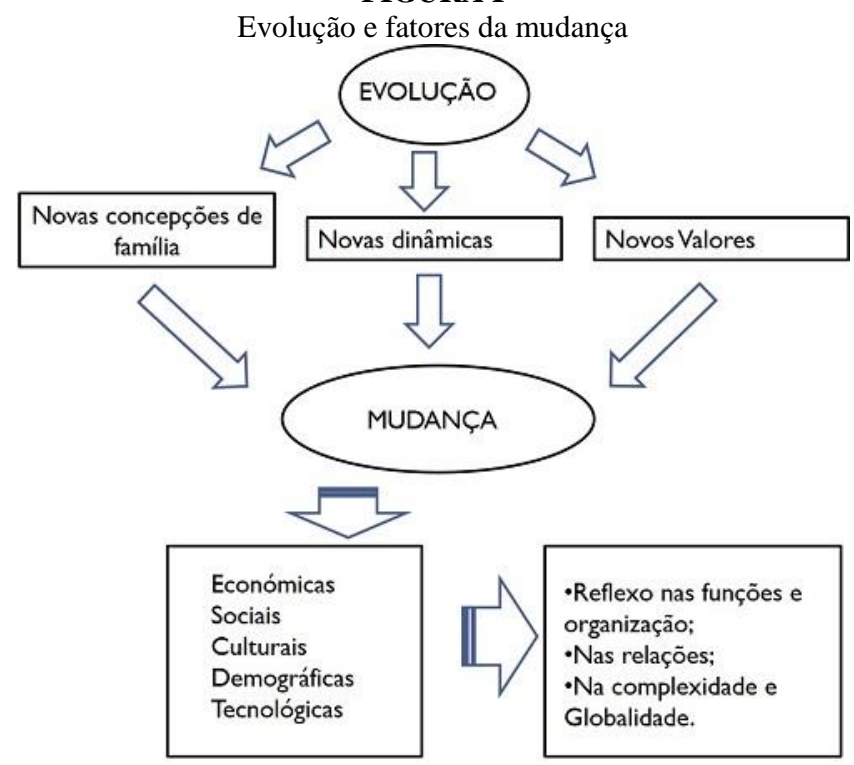

O reflexo destas mudanças é um fenómeno de caráter global e complexo refletido em toda a dinâmica e funções atribuídas à família (Dias, 2000, p.82; Fórum Democracia Aberta, 2008, p. 228). É por isso que quando pensamos a família, somos obrigados a reflexões mais profundas e alargadas sobre as especificidades dos diferentes tipos de família como se observa na figura $\mathrm{II}^{2}$ :

2 Família nuclear; monoparental; recomposta; uniões de facto; livres; famílias unipessoais e mais recentemente as famílias homossexuais. Para não massacrarmos os leitores deste artigo, não virão aqui desenvolvidos estes tipos de família uma vez que não acrescentaríamos nada de novo, pois todos eles têm sido tratados de modo abrangente nos manuais sobre a família e em muitos artigos de revistas científicas, inclusive alguns nossos que são citados neste texto. 


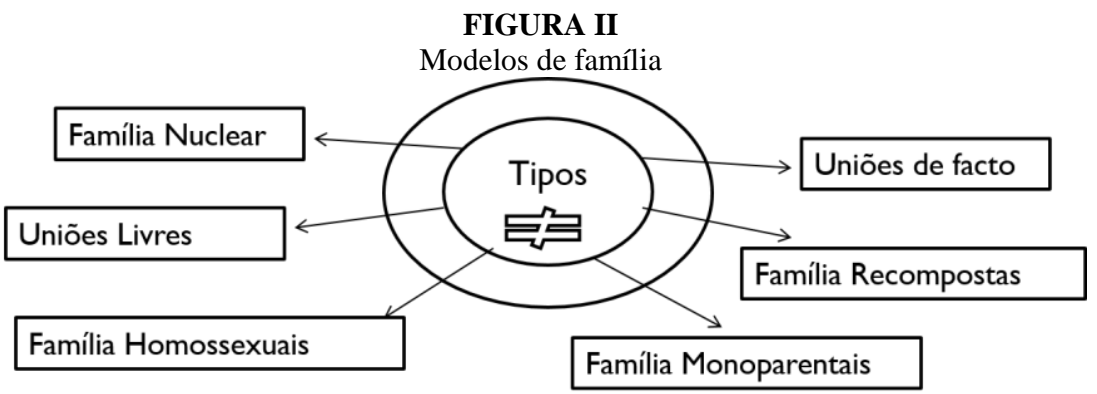

A abordagem da dinâmica interna na família tem sido feita de várias perspetivas, de acordo com o pluralismo que caracteriza a Sociologia da Família (Aboim \& Wall (2002; Fernandes, 1994). É nesta linha, que a diversidade dos modelos familiares é explicada pelos modos como os grupos ou os indivíduos interpretam as normas sociais produzidas num determinado contexto.

Neste sentido, entramos no domínio das interações, onde a coesão que une os membros da família, assenta nas normas e relações, ou não fosse a família um lugar primordial de incorporação e reprodução das diferenças entre homens e mulheres, entre os membros da família (Giddens, 1993; Bourdieu, 1987, 1999).

As dinâmicas da análise das orientações e interações permitem olhar a família enquanto lugar de construção de projetos e de normas que dão sentido às trajetórias familiares e à própria dinâmica interna (Kellerhais \& Troutot, 1989, cit. Aboim \& Wall, 2002, p.490).

Como referimos na introdução, os diferentes tipos de família são, sem excluir nenhum, entidades dinâmicas com a sua própria identidade. As diversas gerações que integram uma família avançam no tempo através do ciclo vital, priorizado por eventos que definem as diferentes etapas de crescimento, assim como as tarefas de socialização, inerentes a cada um dos elementos no percurso que partilham em conjunto (Relvas, 1996; Giddens, 2004; Amaro, 2006; Dias, 2011).

Segundo Paula Relvas (1996, passim) em cada etapa têm lugar acontecimentos que determinam conjunturas que podem afetar cada um dos seus membros, o que exige de todos a necessidade de encontrarem novas formas de estar que lhes permitam adaptar-se às modificações estruturais, funcionais e às mudanças subjacentes a cada etapa ${ }^{3}$. Esta realidade representa-se do seguinte modo (figura III):

\footnotetext{
${ }^{3}$ Etapas que passam pela formação do casal, família com filhos pequenos, família com filhos na escola, família com filhos adolescentes, família com filhos adultos, família com filhos casados.
} 


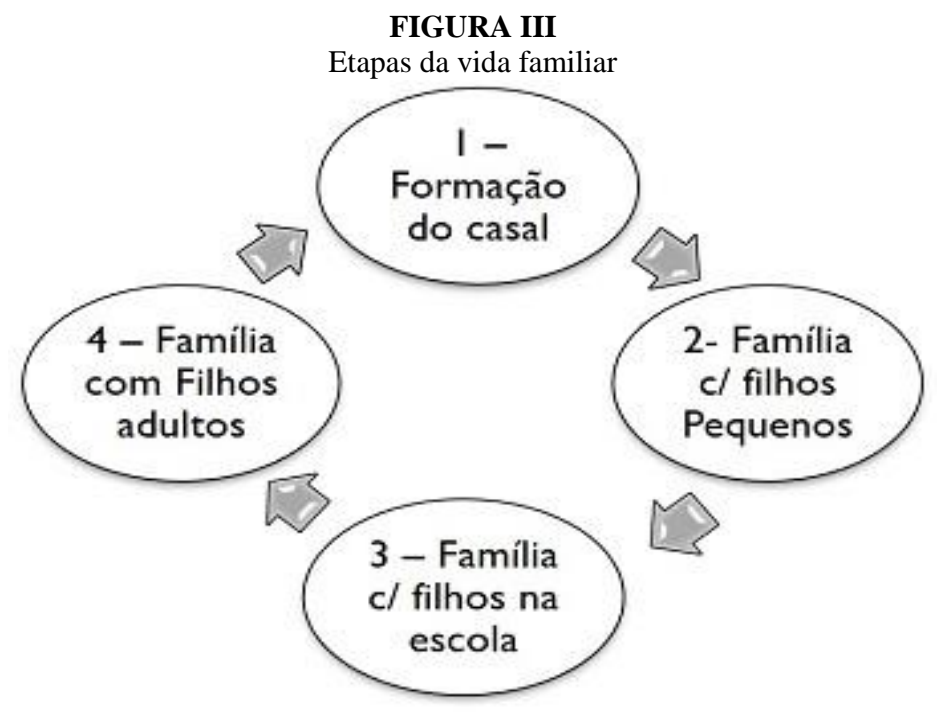

A representação mental que nos é evocada pela palavra família, núcleo constituído por pai, mãe e filhos, que partilham habitação, afetos, convívios quotidianos e entreajudas, não é, de todo uma realidade universal e transversal às diferentes sociedades e culturas, nem aos diferentes períodos que fomos vivendo ao longo da história (Gimeno, 2003, p. 39; Bayle \& Martinet, 2008, p. 25 e ss.).

Mas, além da família como representação mental, é também no sentido a que o nosso senso comum se refere, uma construção social, uma vez que representa um modo de agir e de pensar coletivo, que evolui ao longo do tempo em relação com a organização e o funcionamento da sociedade (Costa, 2004).

Existem sociedades nas quais este conceito não tem aplicabilidade, pois a estrutura funcional, a organização e a relação entre as pessoas é diferente, o que não significa inexistência de laços e regras familiares, mas antes a existência de normas diferentes de organização das relações entre os membros (Ibidem, passim).

A figura IV apresenta a síntese do contributo dado pelos autores citados em relação ao conceito: 
FIGURA IV

A Relatividade do conceito de família

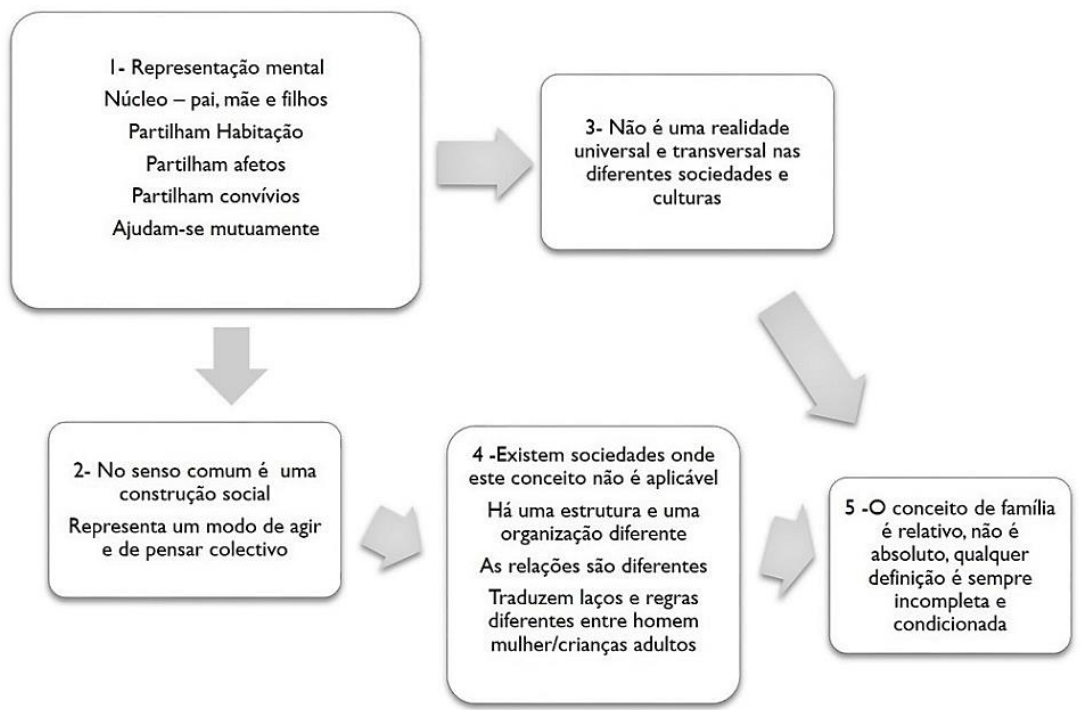

Por conseguinte, não sendo única, a família é, na sociedade, a primeira e mais forte instituição com caráter de socialização, em que a aprendizagem se realiza através da própria experiência de vida familiar. Não esquecendo que, apesar das diferentes modalidades de vida familiar, a família continua a ser vista como um todo, tornando-se necessário então compreender este todo, esta unidade feita de corpos separados. A família é assim, o conjunto das pessoas que a integram e a teia relacional que as unifica.

Neste contexto, Relvas (1996) afirma que a família é o lugar onde convergem sentimentos positivos e negativos, num emaranhado de laços relacionais. Por um lado, queremos manter a ideia da família guardiã, de uma certa segurança, por outro, queremos poder rapidamente renunciar a ela se isso vem contra o desejo individual ${ }^{4}$. Somos pessoas com sentimentos, os quais influenciam as nossas comunicações, o nosso dar e receber.

É no seio da família que se iniciam os primeiros contactos e as relações interpessoais, sendo que o modelo de comunicar se sustenta na comunicação verbal, simbólica (retrato da personalidade) ou não verbal

\footnotetext{
4 A família de hoje, devido às mudanças de que já falamos interessa-se mais pela valorização da vida emocional e afetiva. Face ao casamento de outrora a solidariedade familiar é menos forte, as relações nas famílias atuais são mais distantes do que na família tradicional alargada.
} 
(gestos, silêncio, sorriso, olhar, aparência física, mímica, etc.). A grande importância está na capacidade que cada um tem para induzir sentimentos de segurança nos restantes elementos.

$\mathrm{Na}$ família cada elemento deveria ter a preocupação de ouvir a perspetiva do emissor e não do ponto de vista de si próprio como recetor, pois diminuiriam atritos e ruídos de comunicação o que fomentaria certamente comunicações mais eficientes e saudáveis. São muitas vezes as comunicações, ou a falta delas que conduzem as relações menos boas, conduzindo até a conflitos derivados de incompreensão e que afetam de modo significativo uma interação positiva entre marido e mulher e destes com os filhos.

\subsection{Sobre o Conceito de Comunicação}

Comunicar é uma palavra derivada do termo latino "comunicare", que significa "partilhar, participar algo, tornar em comum (Machado, 1995, p. 197).

A comunicação é um modo de entrar em relação com o outro. É muito mais que uma simples transmissão de informação, é uma relação recíproca entre um emissor e um recetor que se torna, por sua vez emissor (Ferreira \& Dias, 2005, p.95).

A comunicação é um processo interpessoal que envolve trocas verbais e não-verbais. Por um lado, a comunicação interpessoal entre duas pessoas, mas por outro, entre um pequeno grupo, é a que mais se usa na família, uma vez que esta é um grupo que estabelece relações entre os seus membros, manifestadas através da comunicação.

Comunicar está ligado ao adjetivo comum, pôr em comum e ao substantivo comunidade (Carvalho, 1983). Neste sentido, comunicar é tornar algo em comum, pôr em comum, é pois partilhar uma opinião, um sentimento, uma atitude, um comportamento, transmitem-se conhecimentos, experiências, anseios, paixões e estabelecem-se uma série de relações mais ou menos complexas. Assim, comunicar não é mais que comungar, pôr e ter em comum, repartir, compartilhar, tomar a sua parte.

Deste modo, a comunicação não se refere só ao conteúdo mas também aos sentimentos e emoções que as pessoas podem transmitir num relacionamento. Comunicação é um processo de transferência de significado entre as partes. Durante a interação, a comunicação verbal e não-verbal mantêm-se juntas, mas nem sempre a mensagem verbal é igual à não-verbal, dada que nos expressamos de muitos modos. São muitos os autores que consideram a comunicação verbal a forma de construir relações com os outros (Relvas, 1996, Sousa, 2015).

Assim, quando a comunicação se realiza por meio da linguagem falada ou escrita, denomina-se comunicação verbal. Esta forma de 
comunicar é exclusiva dos seres humanos. As outras formas de comunicação recorrem a sistemas de sinais linguísticos (gestos, expressões faciais, imagem, etc) denominados comunicação não-verbal.

Com efeito, a revelação de cada forma de comunicação, neste caso na família, facilita a reciprocidade na relação, além de ser um fator encorajante, no estabelecimento de relações mais próximas e portanto interações mais ricas entre todos os membros.

Concordamos com Riopelle citada por Berger \& Poirier (1995, p. 147) quando diz que a comunicação é "um processo dinâmico verbal e nãoverbal que permite que as pessoas se tornem acessíveis umas às outras, que consigamos pôr em comum sentimentos, opiniões, experiências e informações".

Os elementos da comunicação relacionam-se entre si como ilustra a figura $\mathrm{V}$.

FIGURA V

Modelo de comunicação

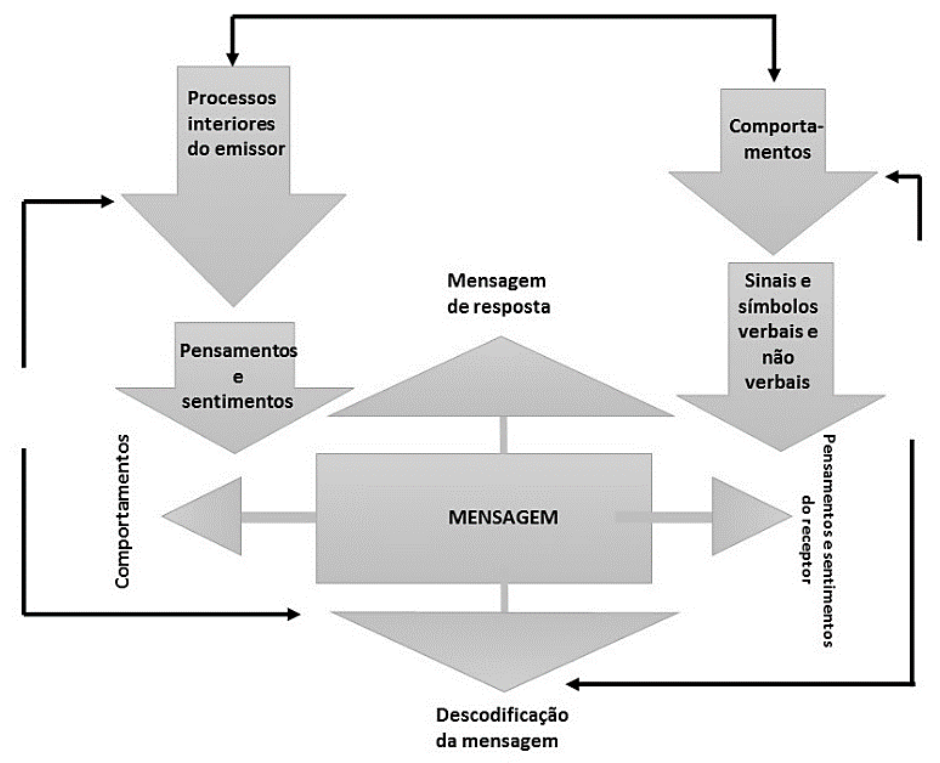

Se não existe o não comportamento e todo o comportamento emite uma mensagem, não se pode deixar de comunicar mesmo quando a comunicação não é intencional. A simples presença ou ausência de uma pessoa, num determinado local onde estava a ser esperada são formas de comunicação (Watzlawick, Beavin \& Jackson, 1993, p.45). 
Estas considerações, acerca da comunicação, evidenciam a ideia de que todo o comportamento tem uma mensagem, seja ela de que ordem. Não dizer nada, ou não fazer nada, também é uma mensagem. Depois de uma mensagem ter sido enviada não há maneira de a trazer de volta, ou seja, toda a comunicação é irreversível, sendo que ninguém pode não comunicar, dado que mesmo estando calados, estamos em interação, provocando reação nos outros.

Concluindo podemos dizer que, desde o princípio dos tempos, a comunicação tem assumido importância vital, sendo uma das principais ferramentas de interação e integração entre os seres humanos que partilham informações tão úteis para cada um na vida da família como para a vida da sociedade.

\section{A COMUNICAÇÃO NO SISTEMA FAMILIAR}

Neste ponto propomo-nos analisar e evidenciar a importância da comunicação, entendida como expressão geradora de diálogo, no sistema familiar e como fator determinante das relações subjacentes no processo. Sem dúvida os membros da família interagem e influenciam-se mutuamente. Mas também, de igual modo, os conflitos familiares estão relacionados com distúrbios na comunicação, adquirindo um caráter muito próprio na organização do quotidiano da família.

De acordo com a teoria geral dos sistemas, nada acontece isoladamente e qualquer coisa que afete um dos componentes, afeta todos os outros, ou seja, qualquer alteração causa impacto sobre todos os outros membros do sistema (Alarcão, 2006; Andrade \& Martins, 2011, p. 188; Dias, 2011, p.147).

Assim, a família, enquanto sistema, é composta por objetos e relações, contendo subsistemas, faz parte de variados sistemas relacionados entre si de forma hierárquica, com limites e fronteiras entre todos os seus elementos (Alarcão, 2006; Dias, 2001c).

A teoria sistémica constitui o modelo predominante dos estudos relacionados com a comunicação, identificado como sendo um sistema aberto com uma finalidade e autorregulado. Sistema quer dizer uma unidade formada por membros que interagem entre si, havendo entre eles determinados vínculos e mantendo-se certas transações (Gimeno, 2003, p. 41; Amaro, 2006, p.34). Assim, o sistema diz respeito à interdependência de todos os seus elementos, donde resulta a ideia de que o conhecimento da família só é possível se for adotada uma visão de conjunto.

$\mathrm{Na}$ perspetiva sistémica a família tem de ser vista como um sistema que apoia a estrutura hierárquica dos seus membros, constituída em subsistemas, ou seja, um sistema dentro de outros sistemas e ela própria 
contendo outros sistemas com regras que regulam o relacionamento entre os membros da família (figura. VI).

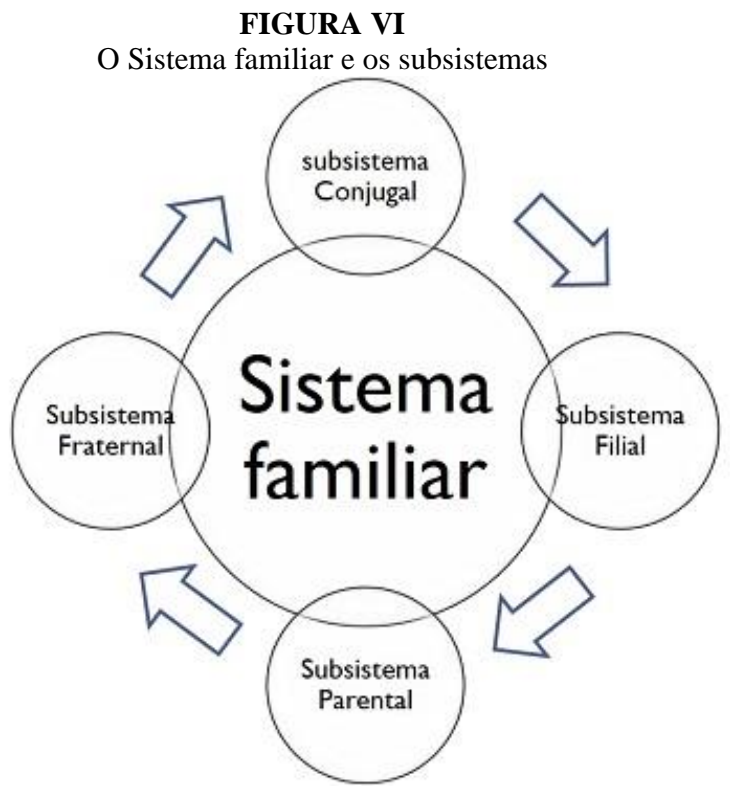

No subsistema conjugal há a presença do eu, do tu e do nós, ou seja, marido e mulher. Este subsistema surge quando dois adultos se unem numa relação interdependente e complementar, formando um casal, identifica as relações entre os cônjuges, poderá significar uma perda em individualidade mas um ganho em sentido de pertença, complementaridade, cooperação, simbiose. O subsistema filial aparece com o nascimento do primeiro filho, que modifica o sistema, seguindo-se outros filhos (hoje talvez o segundo, e raramente o terceiro). $\mathrm{O}$ subsistema parental tem como responsabilidade essencialmente a educação, a socialização e a proteção a todos os níveis. Com efeito, o subsistema fraternal estabelece as relações entre os irmãos, que dentro da normalidade deveriam ser relações fortes descobrindo como cooperar (Relvas, 1996).

A forma como cada subsistema se organiza, e como se desenvolvem as relações dentro de cada um, chama-se estrutura familiar. Todas as famílias se instituem através de uma estrutura de relações, organização específica e única de cada família, traduzindo, na prática, a forma como se organizam os diferentes elementos e como se relacionam entre si. Nas palavras de Baptista e Garcês (2001), a estrutura familiar é fruto de 
transações e comunicações repetidas que levam à definição de padrões de relação.

A família quando encarada como sistema aberto partilha determinadas propriedades sistémicas que se aplicam à interação (Baptista \& Garcês 2001; Alarcão, 2006), sendo elas a totalidade, feedback e equidade ${ }^{5}$. Destes elementos podemos balançar entre a inter-relação e a interdependência dos comportamentos de todos os elementos da família. Relacionam-se e comunicam entre si, a família como unidade ultrapassa a soma dos seus elementos e a mudança num elemento repercute-se no sistema e no comportamento de cada um, sendo indissociável dos restantes, o que acontece a cada um afeta a família no seu todo.

A qualidade das relações familiares tem grande influência no equilíbrio do sistema familiar, seja este de que natureza for, mas essencialmente nas crianças e jovens porque estão ainda a formar a sua personalidade e o seu caráter. Estes têm de confiar em quem os rodeia, aqueles que lhe dão segurança, estabilidade e a certeza que ainda não têm.

Por outro lado, o sistema familiar reage à informação de forma a assegurar a sua continuidade, centra-se em torno de objetivos ou finalidades comuns, embora adaptando-se às diversas exigências impostas com a evolução e a mudança da sociedade. O sistema familiar pode facilitar as trocas adaptativas ajustando as mudanças que se dão no meio ambiente. A comunicação torna-se assim parte integrante do indivíduo na família e na sociedade.

Como a família é a primeira instituição a facultar as relações, o modo como nela se desenvolvem os processos de comunicação determinará o maior ou menor sucesso do desenvolvimento pessoal e social dos seus membros, e consequentemente, a sua integração no sistema familiar e social. Deste modo, a interação caracteriza e expressa o sistema familiar, os sujeitos que dele fazem parte encontram-se num processo de comunicação constante, ao qual não podem subtrair-se. De facto, qualquer comportamento tem sempre o valor da mensagem, pelo que, os elementos de uma família estão sempre em comunicação.

Para Sousa (2015), a comunicação é uma via de acesso para a felicidade familiar. Quando há comunicação entre todos os membros da família, o lar permanece numa esfera de harmonia constante de paz e amor.

Um bom ambiente para comunicar pode ser em qualquer parte e a qualquer momento, em qualquer lugar. Pode ser na sala, na cozinha, no quarto, à hora das refeições, no carro, etc. Na família todos devem

\footnotetext{
${ }^{5}$ Para um desenvolvimento mais alargado destes elementos consultar as obras citadas, não faz parte deste texto o seu aprofundamento.
} 
aprender a comunicar para não deixar o silêncio dominar o sistema familiar e surgirem más interpretações.

Muitas vezes ouvimos dizer: já sabes que gosto de ti, que te amo, não preciso de o dizer, mas, não basta pensar ou presumir que o outro já sabe, é preciso demonstrá-lo constantemente manifestando o contínuo enriquecimento das relações entre todos.

\section{OS DESAFIOS DA FAMÍLIA NA INTEGRAÇÃO DAS CRIANÇAS}

As famílias atribuem aos filhos um valor cada vez maior. Mas, se por um lado verificamos que os filhos são considerados um bem para a família, uma felicidade, por outro lado constatamos que a realidade atual também comporta responsabilidades acrescidas dirigidas diretamente à família, pois os ambientes escolares e sociais são adversos a uma integração plena das crianças. Um estudo empírico, feito por nós (Dias, 2014, p. 57-95), revelou como a família vive receios não só do presente, mas sobretudo o medo do futuro ${ }^{6}$.

Mas também, do ponto de vista do casal são estabelecidas maneiras de interagir que privilegiam, acima de tudo, a satisfação afetiva e relacional, valorizando uma matriz que segue os valores de companheirismo dos cônjuges. Esta tendência não favorece o clima integrativo das crianças, pois traduz um certo comodismo e individualismo. Embora estas observações, continua a ser a família a instituição com maior responsabilidade na integração familiar e social das crianças. Na sua maioria as famílias estão conscientes disso.

Sabemos que a simpatia gera simpatia e que saber escutar é um passo positivo, tanto para a compreensão mútua como para o conhecimento do outro. Sendo assim, deveríamos fazer o treino destas competências a todo o instante para que se torne numa atitude tão natural como beber quando temos sede, ou como comer quando temos fome.

A natureza da interação entre pais e filhos é um fator de primordial importância para o desenvolvimento de todos os membros da família, em geral, mas particularmente das crianças. Dos estudos feitos, embora o assunto tenha sido abordado de diversas posições teóricas, as conclusões gerais são universais e inegáveis (Bayle \& Martinet, 2008). O modo como o pai e a mãe atuam perante o seu filho influencia, direta ou indiretamente, para o bem e para o mal, o comportamento do mesmo (Gameiro, 1994).

\footnotetext{
${ }^{6}$ Mas não só o ambiente escolar e social, também o ambiente familiar apresenta grandes desafios, há razões prioritárias para o casal, observamos uma certa instabilidade que dificulta toda a dinâmica da integração das crianças.
} 
De acordo com Bayle e Martinet (2008; Marques, 2001) a descrição de estilos parentais e suas consequências tem constituído uma das abordagens à questão de como melhor educar uma criança. A descrição feita descreve três estilos parentais: autoritário, permissivo e democrático. A investigação mostra que o estilo autoritário e o estilo permissivo conduzem geralmente a resultados negativos, enquanto o estilo democrático resulta, em geral, em crianças que têm sentido de responsabilidade, tornando-se cooperativas e amigáveis.

A relação entre pais e filhos assenta em aspetos de vinculação e nos estilos parentais, sustentados em teorias de aprendizagem complexas que tendem a privilegiar as áreas comportamental e cognitiva. Os pais são os privilegiados neste caminho, pois educar, ensinar, formar é tão importante como prever as suas necessidades de segurança ou de alimentação.

Com as crianças, é necessário que elas se sintam à vontade para expressarem as suas ideias e sentimentos, a fim de que possamos conhecê-las e compreender melhor as suas atitudes ou comportamentos. Como adultos, devemos preocupar-nos em falar com tom baixo, amistoso e seguro ${ }^{7}$, utilizar uma linguagem simples e direta, falando com sinceridade. Também a linguagem gestual e o jogo são considerados ótimos recursos para a comunicação com as crianças. Cada interação é uma oportunidade para os pais se relacionarem com os filhos. Uma interação corresponde a qualquer intercâmbio entre os membros da família. A interação ocorre na família através de estímulos, presentes ou ausentes, que exercem qualquer influência na interação do meio familiar.

Se considerarmos a natureza abrangente da interação e do meio, as condições e capacidades dos pais, encontramos essencialmente alguns modos de ensinar os filhos. O exemplo, a intervenção verbal indireta, a intervenção direta e a intervenção física, podendo esta ser negativa ou positiva.

Assim, ensinar pelo exemplo é uma das estratégias mais antigas, mais investigadas e mais eficazes. Normalmente é uma estratégia não planeada, emerge naturalmente da interação e das atividades do dia-a-dia. Mas mesmo numa situação não planeada, é importante que os pais reconheçam o impacto profundo que o exemplo acarreta (Marques, 2001; Bayle \& Martinet, 2008).

\footnotetext{
${ }^{7}$ Um dia destes estava em casa de uns amigos onde estavam alguns casais com os seus filhos. A mãe de dois gritava com eles por tudo e por nada, mas ao mesmo tempo perguntava aos sobrinhos se queriam ir para sua casa, estes respondem que a mãe é que sabe. Porém, um dos filhos, fora daqui dizia para a mãe: "Ó mãe a tia grita tanto com os primos, não gosto nada, tenho medo, não quero mais ir para sua casa, mas gosto tanto dos primos que tu podias trazê-los para a nossa casa, eu gostava muito". Às vezes não prestamos atenção suficiente às crianças e cada uma é diferente da outra, perceber o ponto de vista da criança.
} 
A intervenção verbal indireta refere-se à estratégia de conversar, comunicar, sem manifestar abertamente o objetivo de ensino que essa interação comporta, sendo uma estratégia de ensinar através da formulação de perguntas, relato de contos e outras histórias (Bayle \& Martinet, 2008).

Quando uma criança necessita de apoio e orientação, a nossa tendência irrefletida é para recorrer à intervenção verbal direta. Dizemos à criança, clara e objetivamente, o que deve fazer e o que não deve fazer. Esta forma de intervenção verbal direta chama-se telling. Esta estratégia é especialmente eficaz em situações de perigo imediato.

Por vezes a estratégia de telling é insuficiente para separar a criança de um meio perturbador. Pode ser necessário, numa interação, remover algum estímulo perturbador ou introduzir um estímulo apaziguador. Se um pai se interpuser numa interação retirando um estímulo do meio, a interação é designada por intervenção física negativa. Se, por outro lado, o pai se interpuser, introduzindo um estímulo, a interação é designada por intervenção física positiva (Bayle \& Martinet, 2008). Estes dois tipos podem ser usados simultaneamente. Tal como a intervenção verbal, a intervenção física pode ter uma função informativa, cujo uso apoia o desenvolvimento de raciocínio e autonomia, por exemplo, abraçar uma criança, elogiá-la, depois de ter feito algo admirável.

\section{OS VALORES E A COMUNICAÇÃO: REFERÊNCIAS NA FAMÍLIA}

A adesão a valores, na instituição familiar, estabelece maneiras de interagir na família, privilegiando, acima de tudo, a satisfação afetiva e relacional dos seus membros, procurando que as normas sejam democráticas e aplicadas por todos.

Ora, a comunicação e o exemplo têm influência na família como comunidade, na qual, a partir da infância, se podem aprender os valores morais, se começa a ser livre, mas também a respeitar os outros. A vida de família é uma iniciação à vida em grupo e uma preparação para a vida em sociedade, por isso, podemos referir que a família é expressão primeira e fundamental da natureza humana e social. A família é como a célula num organismo vivo: o elemento mais simples, primário e fundamental da sociedade. Não admira que seja o seu seio o lugar mais apropriado para a transmissão de valores e padrões de conduta, que conduzem não apenas à interação e integração na família, mas também na sociedade.

Figueiredo (1985, p.1006), ao estudar a mudança, os valores e conflitos, destaca que o desejo de autonomia, a assunção de 
desautorização envolvendo por vezes os progenitores, traduz-se por uma perda de amor, autoridade e admiração, realidade que o conflito de gerações exprime numa tensão entre jovens-adultos, é de admitir como muito plausível que esta tensão se vá exprimir em conflitos de valores.

Portanto, dificilmente os conflitos no processo de interação e integração não encontram tradução ao nível dos valores. $O$ desejo de autonomia, as desobediências e as preferências por ideias extrafamiliares, manifestam-se sobretudo nos jovens a partir dos 1516 anos (Ibidem, p.1007; Figueiredo, 1988). Esta realidade tem evoluído cada vez mais nas famílias contemporâneas, dificultando por um lado as relações e por outro a interação entre os membros da família.

Não admira que algumas das Encíclicas se refiram à família e aos seus valores, tornando claro que a família é o lugar adequado para a transmissão não só da vida, mas também para a educação, para o afeto, a estabilidade, etc. A Gaudium et spes (1965) no seu $\mathrm{n}^{0} 52$ sublinha: "A família é uma encruzilhada de várias gerações que se ajudam entre si para adquirir uma sabedoria mais profunda e para harmonizar os direitos das pessoas com as exigências da vida social". É impossível uma contribuição para uma ajuda recíproca e harmoniosa na família se não houver esforço de todos, se não se transmitirem afetos.

Na mesma linha, a Encíclica Familiaris Consortio (1981, 15): "Na família constitui-se um conjunto de relações interpessoais - relação conjugal, paternidade - maternidade, filiação, fraternidade, relações através das quais toda a pessoa humana fica introduzida na família" ${ }^{8}$. Este contributo não pode ser desvalorizado, mas entendido como fator de reflexão para aquilo que nós defendemos na interação e integração na família, as relações saudáveis.

Também os valores humanos têm uma grande importância para a motivação humana. Esta remete sempre para valores humanos verdadeiros, materiais e espirituais. Serão prioritários os valores humanos, embora estejam estreitamente relacionados entre si? (Schmah, 2015). Estes valores são fundamentais no contexto da vida em família. Se os pais optarem por certos valores e se comprometerem com eles, serão transmissores através do exemplo para os filhos, por isso devem encontrar mecanismos e descobrir os valores que para si são os melhores, os que têm maior significado, os que mais convêm à família para o desenvolvimento pessoal de cada membro. Nesta perspetiva, o

\footnotetext{
${ }^{8}$ Não é nossa intenção neste texto o estudo dos valores na perspetiva da Igreja, porém não podíamos ficar indiferentes, pois é a Doutrina Social da Igreja a que mais e melhor tem estudado este fenómeno, concordando nós, ou não, com essa abordagem no seu todo. Todas as interpretações são do ponto de vista social aceitáveis, pois não existem as boas e as más, todas se caracterizam por aspetos positivos e negativos.
} 
comprometimento dos pais com os valores e a organização da vida familiar em torno deles tornar-se-ão atrativos e contagiantes para os filhos (Idem).

Por sua vez Olivero (2015) refere que "A família, sob esta perspetiva, aparece-nos como um museu vivo de valores". Valores vividos pelos pais com naturalidade e que os filhos assumem e interiorizam nas suas vidas.

O mesmo autor ao referir-se à família como um museu vivo de valores não pretende dizer que os pais pendurem os valores nas paredes, como se tratasse de um quadro que passivamente se deve admirar. Os valores familiares constituem, pelo contrário, um dado irrefutável, quase com cunho testemunhal, que vai unido ao comportamento diário dos pais (Idem).

Por outro lado, estes valores que se repercutem na conduta dos filhos, quando os pais, além de os viverem e de os fomentarem, promovem algumas normas e costumes familiares que mostram a presença destes valores. Em consequência, a conduta dos filhos estará motivada desde o princípio.

Para Silva (2009), a família, neste tempo, tem sido posta em questão, pelas transformações da sociedade, sendo submetida a uma série de novos desafios em relação aos valores, defendendo que estes devem ser cultivados todos os dias, sob pena de não ser possível voltar atrás quando desrespeitados ou abandonados.

Existem muitos sinais de degradação de alguns valores fundamentais da família, entre eles: a violência doméstica (todos os dias se ouvem notícias, lemos sobre este flagelo), o número cada vez mais crescente de divórcios, o controle da natalidade, o aborto, a consciência contra os valores familiares que ameaçam a estrutura familiar, o individualismo e o materialismo, a miséria, a fome, etc. (Leandro, 2001; Saraceno \& Naldini, 2003; Silva, 2009).

\section{CONCLUSÃO}

Da análise feita neste artigo podemos tirar algumas conclusões:

A família constitui um recurso riquíssimo para o desenvolvimento harmonioso, coerente, sadio e equilibrado dos jovens que nascem e crescem no seu seio. A família tem recursos naturais únicos, capazes de constituir uma marca indelével na estrutura da personalidade dos elementos que a ajudaram a edificar.

A família detém competências e potencialidades diferenciadas, passíveis de criar oportunidades de interação e integração dos elementos que a constituem, tendo por base as suas práticas educativas e formativas, os aspetos de interação e de comunicação, os laços de afeto que os unem 
e os sentimentos de controlo e domínio na consecução dos seus projetos internos específicos. As famílias têm necessidades que a todo o custo tentam suprir. Mas também têm sonhos e objetivos a alcançar, centram-se nas suas aspirações, com um fio condutor de ação, tentando promover relações de cooperação para que juntos atinjam o tão desejado sucesso na vida.

A família, constituindo um sistema, tem de sentir o domínio das suas capacidades, tem de sentir que consegue mobilizar os seus saberes, espelhando competências e um poder de intervenção que lhe é peculiar, pois é essa capacitação e a forte ligação que fundamenta o fortalecimento de tomadas de decisão em conjunto e dos laços familiares que unem os seus elementos.

Mas, nem sempre a família é lugar de diálogo, nem sempre os filhos são apreciados como um dom, mas como um peso e uma pesada responsabilidade. Mas também os filhos nem sempre respeitam as condutas e os valores dos seus pais. De certo modo, estas observações têm na sua base a condição em que a família é muitas vezes vítima da sociedade.

A família, como referimos, é a primeira escola dos valores essenciais, resistindo a possíveis mudanças menos positivas para o equilíbrio do sistema familiar no seu conjunto. A família não é somente o lugar de crescimento pessoal, dos afetos, da transmissão da cultura entre as gerações, é também uma comunidade de amor, o lugar do direito e do princípio do cuidado, da solidariedade, partilha, amizade, companheirismo, respeito e unidade (Silva, 2009). É o elemento mais seguro e mais estruturante da personalidade da criança. É o mais rico ponto de abrigo de qualquer cidadão, é o amor mais real que existe na vida das pessoas. É o local privilegiado para a formação do caráter de um jovem, sendo que os adultos desempenham um papel decisivo no pleno desenvolvimento das capacidades, atitudes e valores que sustentam as competências do sistema como um todo.

Portanto, a família é o lugar e ao mesmo tempo o instrumento mais eficaz, de humanização e de personificação da sociedade. A família, comunidade natural, contribui de modo único e insubstituível para o bem da sociedade. Ela é a primeira sociedade humana, tendo em vista que é uma comunhão de pessoas. Deste modo, a família contém valores tão perenes que jamais podem ser desprezados.

Sendo a família escola de valores exercidos em favor do bem comum, dos seus membros e da sociedade, mesmo diante das maiores adversidades e desafios do nosso tempo deve estar ancorada nos valores que defende e viver a esperança que a fortalece.

A comunicação é então o fator principal a estruturar pois é nela que assentam as práticas de interação formativa, relacional, educativa, afetiva 
e de integração dos elementos que constituem a família. Uma vez que as interações são várias, as relações familiares assentes em processos de comunicação permitem o equilíbrio do sistema.

Estudos empíricos realizados por Figueiredo (1985, p.1018) concluíram que os valores pessoais e relacionais (harmonia, liberdade, amizade, realização, etc.) se sobrepõem aos valores sociais. Neste sentido, os jovens têm preferência em relação aos pais, valores que repousam na relação do indivíduo com o próprio, valores intrínsecos, autoafirmativos, de autorrealização como por exemplo: corajoso, imaginativo, aberto, ambicioso, prazer, felicidade, etc., os pais preferem os valores morais, como: educado, prestável, tolerante, obediente, controlado, etc. Assim, podemos admitir que estamos perante uma evolução dos valores cada vez mais pessoais, de autorrealização para um maior individualismo, maior liberdade dos jovens. Realidade bem diferente da dos seus progenitores o que muitas vezes origina um choque entre os valores de uns e outros.

Daqui, pensamos ser importante fomentar e valorizar os canais de comunicação entre os pais e os filhos e vice-versa. As responsabilidades correspondem a um crescimento saudável, na integração dos indivíduos, em primeiro lugar na família, seguidamente na sociedade. É necessário uma cultura de responsabilização, adequada às capacidades de cada um, que são diferentes não só em relação à idade mas também às funções de pai, mãe, e filhos. Esta concretização vem consolidada através de hábitos e da participação de todos na vida e dinâmica familiar.

\section{REFERÊNCIAS BIBLIOGRÁFICAS}

Aboim, S. \& Wall, K. (2002). Famílias, Análise Social, vol. XXXVII (163), Lisboa: ICS, p. 475-506.

Alarcão, M. (2006). (Des)equilíbrios familiares: uma revisão sistémica, ( $3^{\mathrm{a} e d .}$.) Coimbra: Quarteto.

Alarcão M. \& Relvas, A. P. (2002). Novas formas de família, Coimbra: Quarteto.

Amaro, F. (2006). Introdução à sociologia da família, Lisboa: Instituto Superior de Ciências Sociais e Políticas.

Andrade, A. \& Martins, R. (2011). Funcionalidade familiar e qualidade de vida dos idosos, Revista Millenium, ${ }^{\circ}$ 40, Viseu: Instituto Superior Politécnico, p. 185-199.

Baptista, F. \& Garcês, I. (2001). A família e intervenção social In Silva, L. (cord). Acção social na área da família, Lisboa: Universidade Aberta. 
Bayle, F. \& Martinet, S. (2008). Perturbações da parentalidade, Lisboa: Climepsi.

Berger, L. \& Poirier, M. D. (1995). As pessoas idosas: uma abordagem global, Lisboa: Lusodidacta.

Bourdieu, P. (1987). Choses dites, Paris: Minuiti.

Bourdieu, P. (1999). A dominação masculina, Oeiras: Celta.

Carvalho, H. (1983). Teoria da linguagem: natureza do fenómeno linguístico, vol.1, Coimbra: Coimbra Editora.

Costa, M. I. B. (2004). A família com filhos com necessidades educativas especiais, Revista Millenium, $\mathrm{n}^{\circ}$ 30, Viseu: Instituto Superior Técnico, p. 74-100.

Dias, M. O. (2000). A família numa sociedade em mudança problemas e influências, Gestão e Desenvolvimento, $\mathrm{n}^{\circ}$ 9, Viseu: UCP, p. 81-102.

Dias, M. O. (2011). Um olhar sobre a família na perspetiva sistémica - o processo de comunicação no sistema familiar, Gestão $e$ desenvolvimento, $\mathrm{n}^{\circ} 19$, Viseu: UCP, p. 139-156.

Dias, M. O. (2014). O modelo de procriação real versus ideal - O valor dos filhos, Revista Millenium, $\mathrm{n}^{\circ}$ 46, Viseu: Instituto Politécnico, p. 57-80.

Dias, F. N. (2001c). Padrões de comunicação na família, uma análise sociológica, Lisboa: Instituto Piaget.

Ferreira, M. M. C. \& Dias, M. O. (2005). Ética e profissão relacionamento interpessoal em enfermagem, Loures: Lusociência.

Fernandes, A. T. (1994). Dinâmicas familiares - Harmonia e conflitos, Análise Social, (129), p. 1149-1191.

Figueiredo, R. (1985). Mudança, valores e conflito de gerações em Portugal, Análise Social, Vol. XXI (87-88-89), p. 1005-1020.

Figueiredo, E. (1988). Portugal os próximos 20 anos - conflito de gerações conflito de valores, Vol. II, Lisboa: Fundação Calouste Gulbenkiam, p. 7-9.

Fórum Democracia Aberta (2008). Evolução das famílias em Portugal [Em linha]. Consultado em 2 de fevereiro de 2015. Disponível em http://www.democraciaaberta.com/democracia_forum/ver_topico.php $? \mathrm{t}=295$.

Gameiro, J. (1994). Quem sai aos seus..., Porto: Afrontamento.

Giddens, A. (1993). The constitution of society, Cambridge: Polity Press.

Giddens, A. (2004). Sociologia, Lisboa: Fundação Calouste Gulbenkian.

Gimeno, A. (2003). A família - o desafio da diversidade, Lisboa: Instituto Piaget.

Leandro, M. E. (2001). Sociologia da família nas sociedades contemporâneas, Lisboa: Universidade Aberta.

Machado, J. (1995). Dicionário etimológico de língua portuguesa, Lisboa: Livros Horizonte. 
Marques, R. (2001). Educar com os pais, Lisboa: Ed. Presença.

Otero, O. (2015). Valores na família - Educar na família [Em linha]. Consultado em 5 de fevereiro de 2015. Disponível em http://familia.aaldeia.net/valores - na família.

Paulo VI (1965). Gaudium et Spes Roma: Vaticano.

Paulo II (1981). Encíclica Familiaris Consortio, Roma: Vaticano.

Relvas, A. P. (1996). O ciclo vital da família, perspetiva sistémica, Porto: Afrontamento.

Saraceno, C. \& Naldini, M. (2003). Sociologia da família, Lisboa: Editorial Estampa.

Schmah, E. G. (2015). Os hábitos familiares e a transmissão dos valores [Em linha]. Consultado em 5 de fevereiro de 2015. Disponível em http://familia.aaldeia.net/os hábitos-familiares-e a transmissão de valores.

Silva, J.O.G. (2009). A família e seus valores em meio às ameaças e desafios no nosso tempo [Em linha]. Consultado em 5 de fevereiro de 2015. Disponível em http://www.werbartigos.com/artigos/a-familia-e seus valores.

Sousa, F. (2015). A importância da comunicação familiar [Em linha]. Consultado em 2 de fevereiro de 2015. Disponível em http://família.com.br/a-importancia-da-comunicaçao-fam.

Watzlawick, P., Beavin, J. H. \& Jackson, D. D. (1993). Pragmática da comunicação humana. Um estudo dos padrões, paradoxos da interação ( $9^{\mathrm{a}}$ ed.), S. Paulo: Cultrix. 